\title{
INVITED FORUM
}

\begin{tabular}{|c|c|}
\hline & $\begin{array}{l}\text { Journal of Communication Pedagogy } \\
\qquad 2020, \text { Vol. 3,11-19 }\end{array}$ \\
\hline $\begin{array}{l}\text { COMMUNICATION } \\
\text { PEDAGOGY }\end{array}$ & $\begin{array}{r}\odot \text { The Author(s) } 2020 \\
\text { Reprints and permissions: http://www.csca-net.oro }\end{array}$ \\
\hline & $\begin{array}{r}\text { DOI: } 10.31446 / J C P .2020 .03 \\
\text { Central States Communication Association }\end{array}$ \\
\hline
\end{tabular}

\section{COVID-19 and the Pedagogy of Culture-Centered Community Radical Democracy: A Response From Aotearoa New Zealand}

\author{
Mohan J. Dutta, Gayle Moana-Johnson, and Christine Elers
}

Keywords: COVID-19, culture-centered pedagogy, radical democracy, communicative equality

\begin{abstract}
In this essay, drawing on our ethnographic work at the "margins of the margins" in Aotearoa New Zealand, we depict the role of communicative pedagogy for radical democracy in sustaining spaces for community participation in pandemic response. Based on accounts offered by community advisory group members and observations of emergent community spaces of co-operation amidst the pandemic, we suggest that the ongoing work of building co-creative pedagogy for "habits of democracy" is vital to community response. The work of learning to learn together the habits of radical democracy in communities is permanent work that prepares communities for crises, simultaneously building anchors for imagining radically transformative futures.
\end{abstract}

Drawing on the key tenets of culture-centered pedagogies in communities at the global margins in co-creating voice infrastructures for health and well-being, we suggest that community spaces are key sites of mutual aid in responding to health crises such as Coronavirus disease (COVID-19). The pedagogy of the culture-centered approach (CCA) in communities at the global margins co-constructs "habits of democracy" (Spivak, 2012) as the basis for identifying challenges to health and well-being and organizing around community-led solutions (Dutta, 2008; 2011; 2015; 2016). Culture-centered interventions co-create communication infrastructures for voice, anchored in a culturally rooted pedagogy of community organizing, advocacy, and activism (Dutta et al., 2019). Our team of academics, activists, advocates, and community researchers begin with seeking to understand the meanings of the concepts of dialogue, empathy, listening, imagination, voice, engagement, and research within the

Mohan J. Dutta, Gayle Moana-Johnson, and Christine Elers, Massey University, Palmerston North, New Zealand

CONTACT: M.J.Dutta@massey.ac.nz 
contexts of community life. Based on these understandings, we co-construct tools of teaching these concepts in communities at the margins, crystallized through the cultural values, worldviews, and narratives emergent from within communities. Community workshops are co-created as learning infrastructures for both teaching and learning these concepts from within the rhythms of community life and community negotiations through ongoing dialogues.

Our ongoing work at the Center for Culture-Centered Approach to Research and Evaluation (CARE) in Aotearoa New Zealand has co-created community infrastructures for communities negotiating poverty. A critical proportion of this work is anchored in Māori and Pasifika communities in Aotearoa New Zealand because of the settler colonial policies that have led to the ongoing structural attacks on Māori and Pasifika communities (Dutta \& Elers, 2020). Our community advisory groups and community networks emerged in these spaces as infrastructures for negotiating COVID-19, for responding to the political economic impact of the pandemic, for sustaining as families (whānau), for supporting the marginalized and vulnerable within communities, and for advocating for policy responses. Amidst the deep inequalities that are brought to bear, reproduced, and magnified by COVID-19 (Dutta, 2020; Dutta \& Elers, 2020; Roy, 2020), the CCA, as a method of organizing for communicative equality at the margins, emerges as a resource for intervening into unequal and undemocratic structures that reproduce raced, classed, gendered inequalities. Based on ethnographic insights drawn from community advisory groups created by ongoing processes of co-creative pedagogy, we argue in this essay that the work of the pedagogy of radical democracy in communities is permanent work that prepares communities for crises, simultaneously building anchors for imagining radically transformative futures. The extreme neoliberal reforms inaugurated globally through the deployment of violence amidst a manufactured crisis thrive on the production of crises, with each crisis serving as the basis of deregulation and rollback of the welfare functions of the state.

\section{Learning to Learn From Below}

The work of radical pedagogy is multifold, rooted in the Gramscian exploration of the relationship between pedagogy and transformative politics (Gramsci, 2005). First, in its anti-colonial commitment to dismantling the settler colonial institutions we inhabit from our positions of postcolonial/indigenous privilege (albeit with different layers of privilege, connected to the hierarchies of positions the three of us occupy, a Māori community researcher/advocate, a Māori graduate student, and an immigrant Full Professor; two of us occupying the precarious positions at the Center are women, while one of us is an upper-class man and the Director of the center), radical pedagogy offers an invitation to developing the practice of "learning to learn from below" (Spivak, 2012, p. 439). Decolonizing pedagogy itself is the work of working on the cognitive body of the academic, on "learning to unlearn" our privileges by "learning to learn from below" (Dhawan, 2013; Spivak, 2012). This work of "learning to learn from below" in the words of Gayatri Spivak grapples with the question of what does it mean to engage with colonial structures of education, knowledge generation and democratic participation, anchored in subaltern imaginaries (G. H. Smith, 1997).

Note here the question of communicative engagement as a form of pedagogy turned on its head, inviting us to perform the active work of locating our scholarly commitments outside of the hegemonic structures of the dominant settler colonial institutions we inhabit, which Spivak (2012) terms as the work of rearranging our desires. The recognition of the ongoing subalternity produced by settler colonial knowledge structures in the global North and in the English-engaged metropoles of the global South is an entry point to a politics of active dismantling of these structures by performing the everyday work 
of co-constructing pedagogies of community-anchored habits of democracy. In the context of Aotearoa New Zealand, Māori struggles to build discursive registers for resistance by organizing through the Te Tiriti o Waitangi have resulted in the articulation of the Kaupapa Mãori movement as the basis of radical pedagogy (G. H. Smith, 1997). This ongoing struggle of decolonization has resulted in the securing of Māori language schools and the first indigenous university in Aotearoa.

Our work of "learning to learn from below" takes the form of co-creating community advisory groups, comprised of the "margins of the margins" in communities already existing at the political and economic margins of the settler colonial state. To the extent that a community is circumscribed geographically, it is in Aotearoa rooted in the politics of land loss and forced displacement of Mãori by the settler colonial state. Simultaneously, space as the geographic register for community has gone through rapid transformation, with the large-scale neoliberal reforms implemented across Aotearoa, resulting in concentration of communicative spaces in the service of transnational capital. In workshops anchored in learning the techniques and technologies of communication as resistance as the basis of having a voice in the settler colonial state, we teach the techniques of democratic participation, advocacy, communication strategy, and research.

These concepts are grounded in indigenous sovereignty, emergent from voices of community members that constitute our advisory groups. The CCA brings with it a framework for research democratization and community sovereignty over the research process and outcomes that aligns with the commitment of Kaupapa Māori to whanaungatanga that underpins relationship, kinship, and collective obligation; manaakitanga, nurturing relationships; and aroha, love, respect, and compassion (G. H. Smith, 1997; G. Smith et al., 2012). Our work of teaching is an ongoing inversion of the everyday power structures as the concepts of communicative democracy we teach emerge from ongoing dialogues with those at the margins of communities about the challenges to voice. Moreover, by teaching these concepts and tools in community workshops, we co-create the spaces for listening, where community members identify problems, design solutions, and implement interventions to address the problems.

Communities of care. Our advisory groups emerge as communities of mutual care amidst the crisis. Here is the voice of Gayle, who serves as a community researcher as well as a member of our advisory group, "our main value within the Highbury advisory group is helping whānau in our community." Since the onset of the alert system in Aotearoa, the advisory group has been running on crisis mode, with an emphasis on identifying the critical community needs and on healing each other. The kaupapa (agenda as well as philosophy) has been based around creating a community-grounded crisis response model, drawing on the key lessons of organizing for support within the community. Therefore, helping whannau in need has been the top priority for advisory group members. The Highbury advisory group managed to pull together some food parcels and gift these to whannau in need. It quickly came to the agreement that offering kai and providing material support to those at the margins during this time were key. This also meant our advisory group had to develop an infrastructure for identifying those at the "margins of the margins" and those that are vulnerable (Kaumātua above 60, because of the disproportionate risk burdens borne by Māori and Pasifika communities).

Our community researcher created a video for whānau about keeping safe (in terms of both practices of hygiene as well as practices of promoting mental health and well-being). The community of care emergent from the advisory group articulated strategies for reaching out to the community with the message of staying home. Advisory group members noted that what staying home meant needed to be culturally anchored, because the meaning of staying home is intrinsically tied to the meaning of 
family (whānau, in Māori and Pasifika contexts). Through conversations, the advisory group noted the complexities of the message "stay home" when embedded within the lived experiences and struggles of Māori and Pasifika communities. Our roles as researchers turned into performing the work of care, calling to check on Kaumātua, bringing them food and services, connecting Kaumātua in need to related services, and advocating for specific needs articulated by advisory group members. That mutual care forms the foundation of community response to crisis is an emergent theme in the lessons developed by advisory group members. Our roles then in these networks of care turned to supporting community members at the "margins of the margins." Noted Ngā Hau:

Much of my everyday work turned into seeking out resources to meet community needs, making connections, and following through. This was undergirded by care, which has formed the basis of how we relate to our advisory groups. In the first week after the lockdown, I spent time on the phone wanting to make sure our community members at the margins had access to food, identified the households without food access, and advocated to iwi and Māori providers. I referred 12 whānau requests for food to iwi and Senior Social Service and one to Gayle, our community researcher in Highbury. I followed up on six undelivered requests and stayed on the phone with one whānau member experiencing anxiety while she waited for her food package. I received feedback from community members that there is a 1-2 week delay to get an appointment at Feilding Medical Centre, contacted 4-5 iwi and Māori providers for support. I also emailed the regional health authority.

The pedagogy of care as the anchor to research practice fundamentally transforms what research practice looks like in the context of community life and community response to the crisis.

Advocating into the structures. Communication is constituted amidst existing material inequalities, and our community advisory group members note that these material inequalities are further entrenched amidst crises. With ongoing job losses, economic uncertainty, and uncertainty about rapidly emerging policies, the community advisory groups, community researchers, and our research team converged on the immediate necessity of communicating into structures. One of us, Ngā Hau, responded to three whānau requests for further information regarding employment policies in response to COVID-19, read their letters from employers, and rang them to offer feedback. Ngā Hau's research role was turned into negotiating the rapidly changing information environment around worker rights and workplace policies. For instance, the New Zealand government announced a wage subsidy package to be delivered through employers. This meant that community members needed information on whether their employers had signed onto these wage subsidy packages. Ngā Hau's research role focused on finding employers' lists of those who have accepted the wage subsidy package, calling up relevant ministry resources, and following up on these calls. The work of communication advocacy thus emerged in the everyday negotiations of work. Income, health, and well-being were voiced by community members. The ongoing role of keeping informed about the government's COVID-19 response packages in relation to the wage subsidy, employers' lists, health resources, where to locate health resources, and sites of community access, was complemented by the ongoing role of distributing the messages among community networks through messenger and texts.

\section{Ongoing Erasures}

Even as community advisory groups emerge as spaces for developing community-led interventions in response to crises, they are limited spatially. The nature of COVID-19, spread through human proximity, 
fundamentally disrupts the physical interactions that constitute advisory group meetings. While organizing within the context of a level four lockdown period, it has been challenging for community advisory group members to arrive at decisions, especially because the communicative act of getting together as a group in an offline space (usually the community library that is a space for community members to get together, with the presence of food, kai) serves as the basis for community action.

Limits of technologies. As we have moved into digital spaces amidst the challenges to meeting faceto-face, our experiences are rife with ruptures. Gayle, who is a member of the advisory group, and a community researcher, noted:

Just being one, seeing what is going on in our community, and making decisions on what we can do to create positive change. We have had to move all our contacts to a mostly online platform. This can have its challenges as some whānau do not have unlimited access to the internet, or their devices they use do not have the capacity to join in on video content uploaded. Another alternative to make contact is through cellphone-or we check in on our neighbours the best we can with social distancing.

These ongoing forms of erasure continually foreground the limits of the communication infrastructures we co-construct in crises.

Notes Ngā Hau:

I went back to some of the 30 people that I interviewed and found some that needed food. For one person, it took three people to find his contact details. He lives alone. He told me he eats once a day from the takeaways on the corner, but all takeaways are closed. The iwi representative organized a food care package for him. I have tried ringing him several times since then but his phone his off, so I sent messages to his contacts. Perhaps he is in contact with them.

This difficulty of getting in touch with advisory group members is constituted amidst our negotiations of challenges as a research team. Ngā Hau further shares:

I haven't phoned them in the past two days because I have no credit-used it all up ringing people about their food needs. I have sent them messages to ask how they are doing. I usually get "we all good" response.

Particularly challenging for many community advisory group members at the margins is the labour and cost of connecting through digital platforms. So far, our advisory group meetings were held mostly faceto-face, with the digital platform (advisory group hub hosted on Facebook) as a space to complement our face-to-face interactions. Advisory group members did occasionally come on the Facebook platform, and the extent of participation on Facebook mostly varied with age, with our kaumātua mostly taking the lead in the offline spaces. For many advisory group members, the community library served as an infrastructure for going online. Here are reflections from Ngā Hau's notes:

One member has been in self-isolation since before the lockdown. His adult daughter is with him. He does not have the capacity to virtually collectivise-looking after his health, which is vital, is what he is doing at the moment. One member lives in an extended whānau situation including their older parent, who has major underlying health issues. They have food access 
at the moment. Another member has said that she has limited capacity to collectivise (safely) as she has five children at home.

We negotiate the limits to participation embedded in the technologies by one-on-one follow-ups. When a collective decision will have to be made, one of us will call up advisory group members, note down their comments on Post-it notes, and introduce them into our discussions. An emergent pedagogy grounded in community life centers itself on the limits of the techno-deterministic model that is often perpetuated as the hegemonic solution to participation during crises.

Margins of the margins. Our community advisory group members have been concerned about individuals or households who may be falling through the cracks and not getting the assistance that is needed during this lock-down period. The learning, our learning as community advisory group members, community researchers, and the academic team, turns into delving into how to know who is at the "margins of the margins" of the community, who is vulnerable within the community, what are the communicative resources used by those at the "margins of the margins," and how to build and sustain connections of material, social, cultural, and mental health support amidst a crisis that fundamentally limits physical contact. Here's a reflection from Ngā Hau:

I am more worried about the whānau member who I cannot contact. He does have underlying health issues and few people can engage in sustained communication with him, let alone following him up.

The ongoing conversations and emergent lessons in the community advisory group center on this question of what methods do we have available to us so the advisory group infrastructure meets the needs of those at the margins within the community. The following excerpt is from Gayle's field notes:

The margins of the margins. For example, those who have lost mahi (sources of income), have limited access to transport, those who are health compromised our kaumatua and solo parents. How can we get the support needed for these whānau? Alongside this, there are worries on limitations on who can go to the supermarket or essential services and others have a fear of going out, as they do not want to get sick. The community already has strong sense of connection. Many have volunteered to go out and get any items that someone may need and drop off to their letterbox. To make sure this works-we will go out only when needed and try to do one trip that also fits in with what is needed for ourselves to limit leaving the home. Palmerston North is lucky to have social and government services working collaboratively to ensure that they can help many whānau who may need assistance during this time. When we come across any information, this is shared in an online platform and members have encouraged or helped someone they know contact services that are needed for that specific whānau. We have worked over the last two weeks in serving as information anchors for the community, letting whānau know that they can reach out to our research team also (which they have), and we have been able to advocate on their behalf as well. Although we are in crisis mode at the moment, our community has really been able to pull together and work together to the best of our ability to ensure that we are all safe during this time.

Note in Gayle's reflections our roles as information anchors, negotiating the dynamic and ever-changing environment amidst the crisis. Even as a wide range of services and resources have been co-created by the council, local voluntary organizations, and iwi, how to locate and navigate these resources is an 
ongoing challenge. Our roles as information anchors embedded in the community, is learning from the "margins of the margins" of the community, embarking on information searches seeking to locate structural resources, and developing communicative resources that point to these structural resources through the co-creation process.

The nature of health communication and our labour as health communicators is shifted from largely translating effective health information to the community to locating and sharing structurally-rooted health information. Also, the pedagogy of crisis communication (Sellnow et al., 2012) shifts mostly to the work of anchoring the message, "stay home" amidst the everyday realities of community life. Our academic and community research team co-created messages grounded in the concept of "staying home" and invited our community advisory group members to create messages. The ongoing labor of a designer and a video content producer on our team equipped us with the capacity to create messages based on scripts and design created by community members. Yet, most community advisory group members articulated they already had access to the key information/message, and wanted to spend their energy supporting each other in the community as well as identifying resources that would support households in navigating the guidelines. Noted Ngā Hau:

I asked for video messages from several members. Then I asked people who I interviewed and three were keen. One wants to do hers on tik tok and not be edited at our end. I would say that the hashtag (created by us in our team based on brainstorming) does not match their reality. \#StayHomeWithCommunity is not their reality, but \#StayHomeWithWhānau is.

Here's a reflection from Mohan:

The content we are producing as a team, whether in the form of research papers, policy briefs, opinion editorials, blog entries, postcard images, and video stories is largely about navigating the various resources amidst COVID-19. For instance, we created a number of videos on different aspects of accessing community resources such as food resources. We are working on one that outlines the steps to follow in accessing benefits, once again driven by the immediate needs of community members. The white papers we have been writing emerge from the everyday challenges being experienced by community members, such as the challenges to seeking testing or the challenges to accessing sick leave for workers in essential services.

In the absence of regular advisory group meetings, our work of advocating the structures is mostly emergent from the everyday contacts maintained with community members over the phone, attending to the voices of those households and whānau at the "margins of the margins." Partnering with the city council, civil society organizations and health providers strengthen our networks in advocating into structures, in locating resources, and in securing these resources. Simultaneously, the white papers emergent out of community articulations of challenges being experienced and potential solutions intervene into the structures, talking back to the structures, and pushing for transformations. The issues emergent from community voices foster openings for partnering with civil society, unions, and collectivized movements in strengthening the anchors for advocacy.

\section{Discussion}

Our culture-centered conversations and co-creations with our advisory groups at the "margins of the margins" in Aotearoa NewZealand suggest the urgency of developing pedagogies of crisis communication 
that are rooted in community voices, that offer anchors for imagining collectively today but, more urgently, for the future. These pedagogies of communication, however, are ongoing pedagogies, rooted in the everyday work of co-constructing democratic infrastructures for subaltern voices at the global margins (Dutta, 2008, 2011; Dutta \& de Souza, 2008). The everyday work of bringing the "subaltern into hegemony" is both embedded in the teaching of the everyday tools of democracy and de-centering these tools by "learning to learn" from the subaltern. Māori concepts of whanaungatanga (relationship, kinship, and collective obligation), manaakitanga (nurturing relationships) and aroha (love, respect, and compassion) de-center the pedagogy of democracy. Democracies of care evident in our advisory groups and community partnerships in Aotearoa are embedded in Māori imaginaries of sovereignty and community self-determination (tino rangatiratanga, see G. H. Smith, 1997).

The structural inequalities that constitute crises and that are furthermore entrenched and magnified by crises form the backdrop of culture-centered pedagogy, drawing from the various strands of organizing through which communities are sutured and imagined together. Our pedagogical work of community democracy through voice carried out in the everyday rhythm of community life serves as the basis for everyday organizing, for imagining alternative futures, for developing advocacy strategies, and for advocating into local, national, and global structures. The emergent model of pedagogy thus is a decolonizing model talking back to the hegemonic structures of Whiteness that constitute the pedagogies of communication and democracy (Basu \& Dutta, 2008; Dutta, 2015, 2016; Dutta \& Pal, 2010). Digital spaces, intertwined with values of aroha and manaakitanga, co-create alternative infrastructures for care and mutual support. Simultaneously, these digital spaces reify and reproduce ongoing inequalities, coalescing with the inequalities that are magnified by COVID-19. The recognition of the agentic capacities of communities as co-creators of democratic possibilities grounded in communicative equality open up both the epistemology and ontology of communication pedagogy to radical imaginaries.

\section{References}

Basu, A., \& Dutta, M. J. (2011). 'We are mothers first': Localocentric articulation of sex worker identity as a key in HIV/AIDS communication. Women \& Health, 51(2), 106-123.

Dhawan, N. (2013). Coercive cosmopolitanism and impossible solidarities. Qui Parle: Critical Humanities and Social Sciences, 22(1), 139-166. https://ssrn.com/abstract=2797879

Dutta, M. J. (2008). Communicating health: A culture-centered approach. Polity.

Dutta, M. J. (2011). Communicating social change: Structure, culture, and agency. Routledge.

Dutta, M. J. (2015). Decolonizing communication for social change: A culture-centered approach. Communication Theory, 25(2), 123-143. https://doi.org/10.1111/comt.12067

Dutta, M. J. (2016). Neoliberal health organizing: Communication, meaning, and politics (Vol. 2). Routledge.

Dutta, M. J. (March 29, 2020). COVID19-India's underclasses and the depravity of our unequal societies. $\quad$ https://web.archive.org/web/20200402205904/https://www.thecitizen.in/index.php/en/News Detail/index/4/18516/COVID19----Indias-Underclasses-and-the-Depravity-of-Our-Unequal-Societies

Dutta, M. J., \& de Souza, R. (2008). The past, present, and future of health development campaigns: Reflexivity and the critical-cultural approach. Health Communication, 23(4), 326-339. https://doi. org/10.1080/10410230802229704

Dutta, M. J., \& Elers, C. (Nga Hau). (March 21, 2020). Why talk about racism during COVID19. https:// web.archive.org/save/https://culture-centered.blogspot.com/2020/03/why-talk-about-racism-duringtimes-of.html 
Dutta, M., \& Pal, M. (2010). Dialog theory in marginalized settings: A subaltern studies approach. Communication Theory, 20(4), 363-386. https://doi.org/10.1111/j.1468-2885.2010.01367.x

Dutta, M. J., Pandi, A. R., Zapata, D., Mahtani, R., Falnikar, A., Tan, N., Thaker, J., Pitaloka, D., Dutta, U., Luk, P., \& \& Sun, K. (2019). Critical health communication method as embodied practice of resistance: Culturally centering structural transformation through struggle for voice. Frontiers in Communication, 4, 67. https://doi.org/10.3389/fcomm.2019.00067

Gramsci, A. (2005). The southern question (Vol. 46). Guernica Editions.

Roy, A. (April 4, 2020). The pandemic is a portal. Financial Times. https://web.archive.org/ web/20200617183618/https://www.ft.com/content/10d8f5e8-74eb-11ea-95fe-fcd274e920ca

Sellnow, T. L., Sellnow, D. D., Lane, D. R., \& Littlefield, R. S. (2012). The value of instructional communication in crisis situations: Restoring order to chaos. Risk Analysis: An International Journal, 32(4), 633-643. https://doi.org/ 10.1111/j.1539-6924.2011.01634.x

Smith, G., Hoskins, T. K., \& Jones, A. (2012). Interview: Kaupapa Māori: The dangers of domestication. New Zealand Journal of Educational Studies, 47(2), 10.

Smith, G. H. (1997). The development of Kaupapa Māori: Theory and praxis (Doctoral dissertation, ResearchSpace@Auckland).http://hdl.handle.net/2292/623

Spivak, G. C. (2012). An aesthetic education in the era of globalization (pp. 335-350). Harvard University Press. 